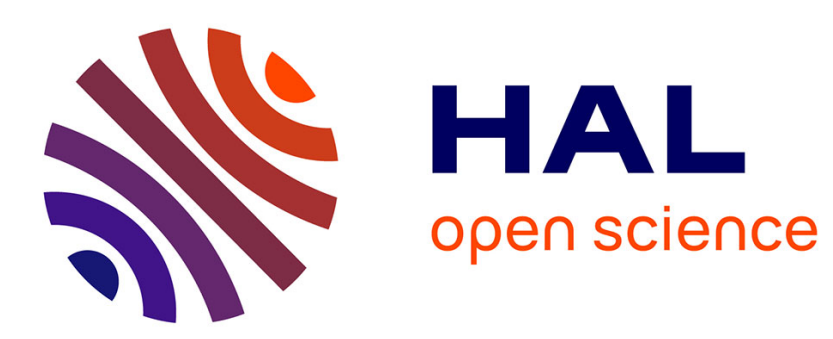

\title{
Methods in Designing and Developing Capabilities: A Systematic Mapping Study \\ Hasan Koç
}

\section{To cite this version:}

Hasan Koç. Methods in Designing and Developing Capabilities: A Systematic Mapping Study. 8th Practice of Enterprise Modelling (P0EM), Nov 2015, Valencia, Spain. pp.209-222, 10.1007/978-3-31925897-3_14. hal-01442253

\section{HAL Id: hal-01442253 \\ https://hal.inria.fr/hal-01442253}

Submitted on 20 Jan 2017

HAL is a multi-disciplinary open access archive for the deposit and dissemination of scientific research documents, whether they are published or not. The documents may come from teaching and research institutions in France or abroad, or from public or private research centers.
L'archive ouverte pluridisciplinaire HAL, est destinée au dépôt et à la diffusion de documents scientifiques de niveau recherche, publiés ou non, émanant des établissements d'enseignement et de recherche français ou étrangers, des laboratoires publics ou privés.

\section{(c)(1)}

Distributed under a Creative Commons Attribution| 4.0 International License 


\title{
Methods in Designing and Developing Capabilities: A Systematic Mapping Study
}

\author{
Hasan Koç \\ University of Rostock, Institute of Computer Science, 18051 Rostock, Germany \\ hasan.koc@uni-rostock.de
}

\begin{abstract}
Enterprises operate in dynamically changing environments that have an influence on both business and IT areas. Capabilities have been proposed as instruments to align business and IT in such environments. One aim of enterprise modelling is a better communication between the stakeholders of an enterprise at various levels. Thus, the alignment can be facilitated by the exploitation of enterprise models as an abstraction instrument. In this respective the paper analyses the methods for capability design and development from the enterprise modelling perspective by conducting a mapping study, i.e. the level of methodological support for capability modelling is investigated. For this purpose 112 journals and 24 conference proceedings were analysed. The most important findings are that the research in capability design i) adopts empirical research, mostly in form of case studies and surveys ii) is mainly motivated by Resource Based View (RBV) and changing environments iii) proposes development approaches and frameworks as solution artefacts, iv) lately receives attention in the Information Systems Development \& Tools of MIS subject classification lately, v) provides a scarce methodological support that is mostly represented as procedures and most importantly vi) only to some extent exploit enterprise models that could enhance stakeholder communication at various abstraction levels.
\end{abstract}

Keywords: Capability Modelling, Capability Development, Method, Systematic Literature Review, Mapping Study

\section{Introduction}

The organizations are operating in an ever-shifting environment. Due to the rapid changes in regulations, globalization, time-to-market pressures and technological advances, the alignment of business and information technology (IT) becomes a serious challenge. Enterprises thus require the agility to adjust their offerings for a sustainable competitive advantage. One way to tackle these challenges is the design and development of the capabilities. As fundamental abstraction instruments in the stakeholder communication at various levels, modelling of capabilities can establish the required alignment [1].

Research in the field of capability management steadily rose during the last decade. However, there is a paucity of articles that systematically investigate methods, 
approaches and procedures in identifying, developing and designing an organization's core capabilities. In terms of the systematic literature reviews the contributions focus on the capability maturity models [7]. This paper presents a systematic mapping study in the methods of the capability design and development by analysing the research topics, research methods and research activities. The findings show that the research in capability design methods i) adopts empirical research, mostly in form of case studies and surveys ii) is mainly motivated by Resource Based View (RBV) and changing environments iii) proposes development approaches and frameworks, iv) receives attention in the Information Systems Development \& Tools of MIS subject classification lately [9], v) provides a scarce methodological support and vi) only to some extent exploit enterprise models that could enhance stakeholder communication at various abstraction levels.

In line with [11] we define a method as a systematic way of problem solving consisting of concepts, activities and notations. The concepts specify what should be captured in a model. The activities describe in concrete terms how to identify the relevant concepts in a method component and the notation specifies how the result of the procedure should be documented. In this respect our findings show that the methodological support in capability development does hardly fit into the aforementioned method framework. The analysed articles propose steps, procedures or guidelines to design capabilities, which only to a weak extent expose the conceptactivity-notation structure. This is investigated in section 4 in detail.

The remainder of the paper is structured as follows. Section 2 describes the research approach, which is a mapping study, a specific type of systematic literature review (SLR). Then section 3 presents the research design, i.e. which literature sources are included in the analysis. Following that, section 4 analyses the findings and section 5 concludes the work.

\section{Research Approach}

The research approach used in this work is a mapping study, which is a specific type of systematic literature review (SLR). A SLR is a review process of prior studies with a structured and comprehensible procedure that aims to accumulate all "existing evidence concerning a treatment or technology" and "identify gaps in current research". Mapping studies are characterized by their wider scope of the study and the generalization of research questions in a broader field [13]. After getting an overview of the research area by for instance defining the research methods, research design and research topics, detailed information can be extracted from a set of publications.

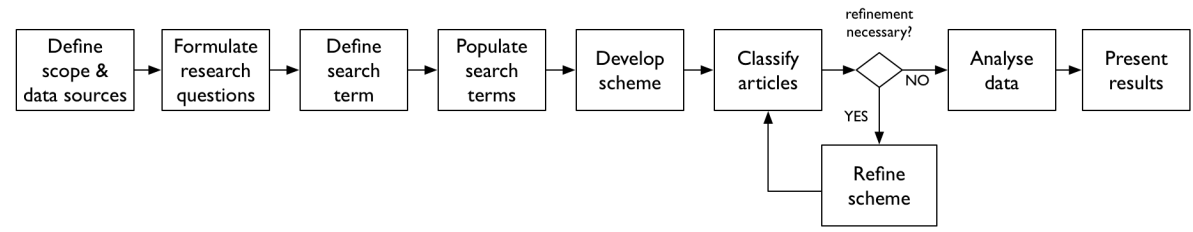

Fig. 1. Steps of the systematic literature analysis 
This work conducted a mapping study and developed a scheme to classify the findings thoroughly. Thus the guidelines of Kitchenham [1] were extended by the develop/classify/refine steps, as illustrated in Fig. 1. The selection process of the journals and conferences during scope definition was exhibited (section 3.1) to provide transparency for researchers who might repeat the analysis by extending the sources or changing the inclusion criteria of journals, conferences or books. After defining the scope (section 1) and data sources (section 3), four research questions (RQ) are formulated, which are answered subsequently in section 4.

- RQ1: Which research methods and research design are used in the capability development field?

- RQ2: Which topics are under investigation in the field of capability design methods? Is it possible to identify a trend in these topics?

- RQ3: Which countries and institutes are active in the field of capability design methods?

- RQ4: Which methods, steps or approaches are proposed to develop and design capabilities?

\section{Review Design}

This chapter introduces the literature sources that are included in the analysis as well as the process of classification scheme development.

\subsection{Selecting Literature Sources and Papers}

Conducting a SLR requires a thorough selection of the data sources that serve as a starting point. To select the literature sources, we first identified A+ and A Journals based on the rankings from [3]. Next, we complemented this list with B Journals from the Business Information Systems sub-discipline. To stabilize the journal selection we crosschecked our results with the rankings from [4] and finalized the journal selection part. After that we populated the list of journals with A and B ranked conferences from [5], with "A" being the highest ranking. As a result we identified a total of 112 journals and 24 conferences.

The main terms used for the initial search were "capability" (in abstract) and "method OR design OR proc*" (in keywords). The keyword terms were populated with the additional terms "practice OR step OR modeling OR modelling". Consequently we searched in the selected sources that included the term \{capability\} in abstract and one of the following terms \{method, modeling, modelling, proc*, design, step, practice $\}$ in keywords. After removing the duplicates and inaccessible articles, the search resulted in a total of 362 journal articles and 178 conference papers.

The selection of the papers was based on a set of criteria, which is applied during abstract reading. In cases where the exclusion or inclusion was unclear, an additional full-text reading is conducted. First of all, the articles are eliminated that did not explicitly address "design and development of capabilities" as their research scope. 
For instance, if capabilities were proposed only as means to leverage the value of a firm's knowledge or mentioned as enablers of enhanced outsourcing arrangements, then it was excluded. Furthermore we eliminated an article when the term capability was used as a synonym for "ability" or "future", i.e. unrelated to its application in the Information Systems. Also the articles were excluded, which use the term capability in the abstract and do not mention it in the narrative text or mention dynamic capabilities to position their proposals as means to gain competitive advantage.

The main purpose in line with the research questions was analysing the state of the research in fields of capability modelling as a subset of enterprise modelling, in particular where processes, procedures, steps or methods are proposed to develop or design business capabilities. Hence the articles are included that address this aspect in a narrower context, i.e. the articles that investigate steps, best practices, guidelines, concepts, notations and roles in developing such capabilities. Most of the journal articles explored the relation between the capabilities of an enterprise as well as its environment and lacked establishing a clear relationship to the enterprise modelling. For the purposes of this paper, this is an interpretation of capability design in a broader context. Still, if the article contributed to capability development method area, then it was included. On the other hand the publications were excluded that investigate how for instance the IT capabilities are interlinked with the provision of egovernment services by applying statistical methods and developing hypothesis. After the application of those criteria, a total of 22 journal articles and 23 conference papers resulted for further analysis ${ }^{1}$.

\subsection{Developing the Classification Scheme}

A classification scheme provides a way to organise and structure the selected papers. The scheme included three main categories, research methods, research design and research topics, which are elaborated in this section.

The starting point for the classification in the category research design was the framework of Alavi and Carlson [12] that on the highest level distinguishes between empirical and non-empirical research. Articles carrying out empirical research capture the essence of research by relying on observation that are supported by data, which is acquired via qualitative (case study, interviews) or quantitative (experiments, surveys) techniques. The research design types are extended with "conceptual articles" and "design science research" articles [7]. Conceptual articles are primarily based on the ideas, frameworks, and suggestions rather than the systematic observation. Design science research articles answer questions relevant to human problems via the creation of innovative artefacts, thereby producing new knowledge and contributing to the body of scientific evidence. Design science research is fundamentally a problem-solving paradigm whose end goal is to produce a useful solution by creating and evaluating an artefact relevant to an IS problem. To be classified as designoriented, the articles should follow the guidelines provided by [8].

${ }^{1}$ The list of the investigated journals, conferences and selected papers can be accessed from http://bit.ly/105sS18 
The category research methods is created based on the article of Palvia et al. [9], which examined the mainstream journals in MIS research in terms of employed methodologies. The structure is expanded in order to fit our research purpose. We first defined "qualitative \& quantitative research" as two main classes of research methods. Then we specified the two method types, systematic literature reviews and experiments. Finally grounded theory was added as an additional research method, which seeks to develop a theory by analysing gathered data systematically [10].

To structure the research topics the "concept matrix" approach was adapted from Webster and Watson [5], where the articles are structured according to their contribution areas. As illustrated in Fig. 1, these research topics were refined whenever necessary. Here three main contribution classes were observed. Motivation analysed the starting point of the articles, which is mostly reflected in the abstracts and state of the art sections. Investigation analysed the topics that the papers explore and contribute in, mostly stated in the conclusion parts. In line with [9] subject classification structured the research endeavour to more general research subjects in the Information Systems discipline. Fig. 2 shows the classification scheme, including the research design, research method and research topics as the main categories.

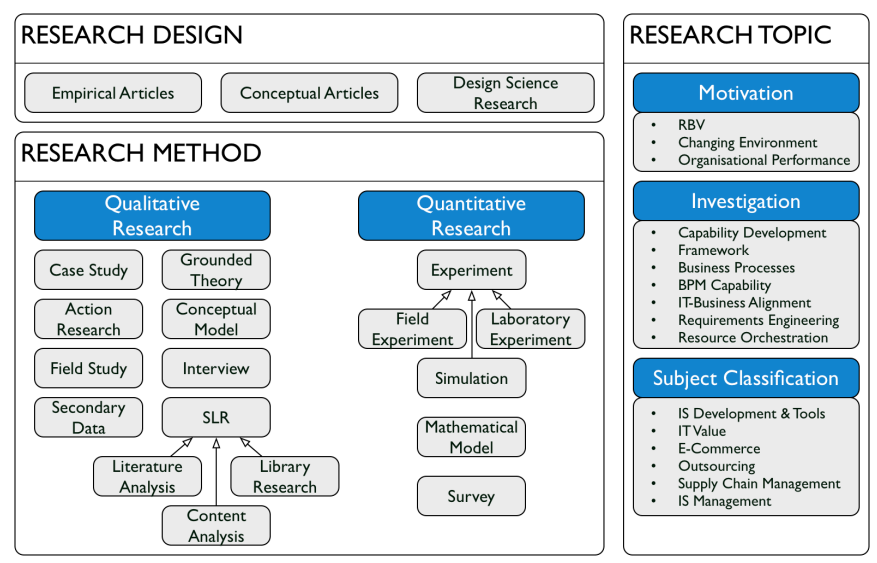

Fig. 2. The classification scheme

\section{Data Analysis}

\subsection{Research Methods and Research Design}

This section classifies the articles in line with their research approach (Fig. 2). The "research design" category is mutually exclusive, i.e. an article can apply only empirical, conceptual or design science research paradigm. On the other hand in the "research method" category the articles may be related to more than one method. To 
exemplify, an article can conduct a case study after a survey and thus use two different research methods. The analysis of all articles has shown that empirical design is used at most in the design of capabilities ( $76 \%$ of all articles). A remarkable result was the application rate of design science research, which only took place in $4 \%$ of all articles.

When conducting empirical research, 2 of 3 articles based their findings on qualitative research methods by applying case studies (38\%), interviews (26\%) and conceptual models $(21 \%)$. The articles adopting quantitative research methods use surveys extensively (55\%). The structure that these articles follow is i) developing hypotheses to investigate the factors, phenomena, abilities, roles influencing design and development of capabilities, ii) conducting a survey and iii) statistically evaluating if the hypotheses hold. The results of such articles might be quite beneficial when constructing methods for capability design. Surveys are followed by secondary data $(36 \%)$, where the authors collect business data such as financial reports, documentations, archival materials and published documents.

The conference papers extensively use qualitative research methods (75\%). In fact, only $2 \%$ of relevant articles apply quantitative methods solely. On the contrary the allocation in journal publications seems to be balanced, i.e. $44 \%$ of all articles conduct quantitative and $56 \%$ qualitative method techniques. In the set of 45 papers, 15 publications combined qualitative and quantitative methods (the exact allocation is 10 journal articles and 5 conference papers). Interestingly 8 of these 15 publications adopt case studies, interviews and analysis of secondary data, which seems to be a research method pattern. Also $80 \%$ of the conference papers combining both qualitative and quantitative methods adopt this pattern.

By allocating 45 papers to three time frames; 2000-04, 2005-09 and 2010-14, we analysed the trend in the research methods applied in the publications. In order to do so, we observed the relation of the selected research method to the sum of the published articles in the time period. Subsequently, there seems to be a trend in the capability design field concerning the application of secondary data and case studies as a research method. Last but not least, the number of articles producing conceptual models based on non-empirical data diminish, interviews and surveys remain stable.

\subsection{Research Topics}

This section analyses the RQ2 and identifies what topics are under investigation in the field of capability design methods and which terms are used most often. To determine the research topics we first analysed the title, abstract and keyword of the publication and summarized the mentioned terms. Next, a full text reading of 45 papers was conducted to limit the number of terms and include only the main focus and contribution of the work at hand. After this we clustered the final terms and classified them into the research topics in line with the developed scheme (Fig. 2), where an article can be related to multiple topics. The clustered topics include following terms:

Resource Based View. Articles motivating their work based on "Resource Based View, Dynamic Capability or Competitive Advantage" are categorized here. This topic is used for nearly half of the total works $(45 \%)$. Obviously these topics address the inspiration in the field of capability design and development methods (Fig. 3). 
IT Value. Includes the terms "IT Capability, Information Communication Technology (ICT), ICT Capability" or "Leveraging IT". This topic is analysed in $38 \%$ of the relevant articles and exposes the importance of IT in capability design.

Changing Environment. Includes articles with the terms "Change in Business, Change Management, Growing Enterprises, Business Model Transformation, Evolving Needs, Different Contexts, Unanticipated Changes, Dynamic Business Environment, Developing Countries, Emerging Economies". 36\% of articles motivate their work based on this topic. This is an indicator that capabilities are used as instruments to deal with agility and flexibility issues based on changing requirements. E-Commerce. Includes the subject terms "E-Service, Electronic Service Delivery, Cloud Computing, Cloud Service, E-Business Strategy, E-Government, E-Business". $\% 27$ of the relevant articles deals with E-commerce topic.

IS Development \& Tools. Includes subject terms "Enterprise Modelling, Goal Modelling, Pattern Modelling, BPM, Business Process Design, Business Models, Context Modelling". \%27 of the relevant articles deals with this topic, all of which are published in conference proceedings. This finding addresses that the capabilities are important abstraction instruments for business and IT alignment and their modelling is closely related to the enterprise modelling area.

IS Management. Includes subject terms "Strategic Management, Strategy Process, Internationalisation Strategy, Strategy Optimisation, Business Strategy Development, Strategic Business".

Outsourcing. Includes subject terms "IT Outsourcing, Business Process Outsourcing, Service Level Agreement, Interorganizational Relations".

In addition to these topics, specific concepts were identified that cannot be structured in the above-mentioned groups, such as "Framework, Capability Development, Business Process, and BPM Capability". Fig. 3 illustrates the results of the research topic classification including both clustered terms as well as specific topics. For brevity reasons, the topics were omitted which were motivated or investigated in less than $10 \%$ of all articles. No trend analysis was conducted for such topics.
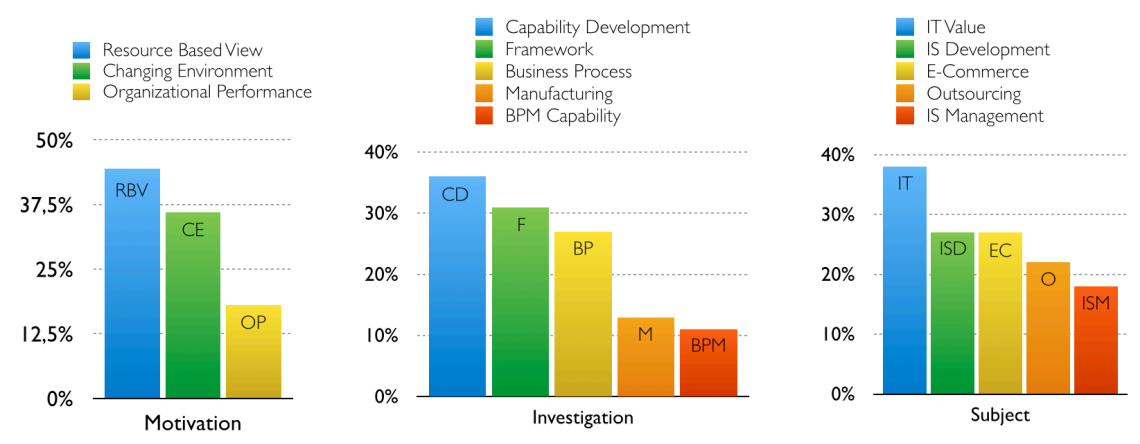

Fig. 3. Research topics in capability design

The analysis shows that concerning some of the aforementioned research topics it is possible to speak of a trend. Here it should be noted that all three classes 
(motivation, investigation and subject) are observed together as illustrated in Fig. 4. The analysis was carried out by simply relating the used terms to the number of published articles in the selected time frame. The trend graphic proves that the contributions are mainly based on the three motivation topics, with a positive trend in the "Changing Environment" and a slight negative trend in the "RBV". Concerning the investigated topics, scholars pay more attention to the "Capability Development" field in the last 5 years and both the "Business Process" as well as the "BPM Capability" have a stable course over the observed 15 years. On the contrary the number of the publications proposing frameworks diminish from 2010 to 2014 in the field of capability design. In terms of the subject areas a negative trend was observed in the topics "E-Commerce, IT Value" and IS Management". This implies that the capability design research has reached a certain level of maturity in these subject areas. Conversely, the topic "IS Development and Tools" gains a recognizable attention, for which we did not find an article between 2000 and 2004. As all the articles covering this topic were published in conference proceedings, we argue that the research trend in the capability design and development is moving lately towards methods, ways, steps, procedures in capability modelling, capability construction as well as relation of capabilities to enterprise models. This view is also in line with our findings from two other topic classes, the motivation (trend in the topic "Changing Environment") and the investigation (trends in the topics "Business Processes, Capability Development, BPM Capability"). Conclusively there seems to be a correlation between "modelling capabilities in the changing environments of the enterprises and their business processes". In other words, the focus in enterprise modelling in changing environments is shifting towards adding an abstraction level with capabilities rather than creating adaptable business process models, which are complex to understand and hard to manage. This hypothesis should be falsified or confirmed in the future work.

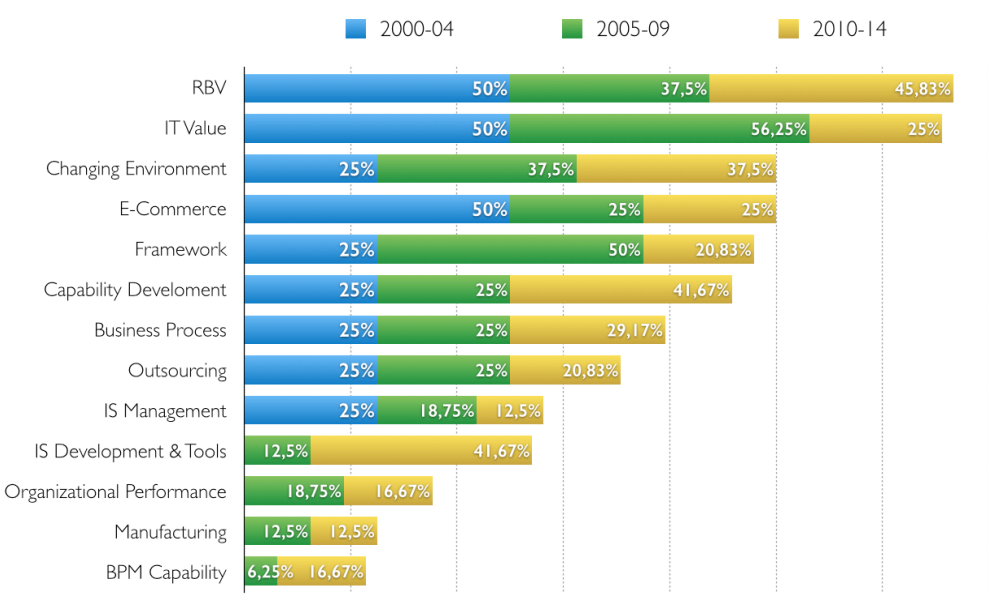

Fig. 4. Trends in topics 


\subsection{Activity in Capability Design and Development Methods}

[14] addressed a new thinking about the organization of IT activities amongst which identifying and developing an organization's core IT capabilities had a significant role. Before this article, we did not encounter any publications focusing on capability design and development; our set included only one article before 2000, which was published in 1988. The analysis of activities shows that the scholars have followed the advice of [14], since the findings expose the growing interest in developing capabilities over the years.

To observe the activities in design and development of capabilities, three time frames were applied from 2000-2004, 2005-2009 and 2010-14. The number of the published articles in this field rose steadily in the conferences. In this context conferences and workshops of International Conference on Advanced Information Systems Engineering (CAiSE) focus most on the design and development of capabilities (30\% of all conference papers) followed by European Conference on Information Systems (ECIS), with 17\%. Please note that the workshops are assigned to the conferences in which they were held. In terms of journals, the scholars are engaged in this field after 2005 and no journal article particularly focuses on capability design and development methods. Although the interest does not increase regularly, the amount of published articles in 2010-14 shows that capability development is still in the focus. This is illustrated in Table $\mathbf{1 .}$

A high amount of contributions to the capability design and development field originates from the institutes in USA (30\%), which are to a very large extent published in journals ( 1 conference and 13 journal papers). On the contrary, Germany, the second country with most contributions (22\%) has provided only 1 journal article and 9 conference papers. The allocation of relevant articles to countries is illustrated in Fig. 5. Here the authors are classified to the nations in accordance with their institutes defined in the publications. Furthermore, a country was not included in the graphic for brevity reasons, if the researchers contributed only once to the field. In this context, three main universities were identified that have contributed mostly to this area, namely Münster University (Germany), Stockholm University (Sweden) and Riga Technical University (Latvia).

Table 1: Classification of articles per time frame and publication source

\begin{tabular}{llll}
\hline & $\mathbf{2 0 0 0 - 0 4}$ & $\mathbf{2 0 0 5 - 0 9}$ & $\mathbf{2 0 1 0 - 1 4}$ \\
Journal & 3 & 11 & 7 \\
Conference & 1 & 5 & 17 \\
\hline
\end{tabular}

Although USA contributes most the field under study, 55\% of all articles originate from Europe, where conferences play a predominant role $(70 \%$ of all European publications). Europe is followed by America (25\%) and Asia (15\%), whereas in America the scholars contribute to this field primarily with journal publications $(84 \%$ of all American contributions). The findings can be exploited for practical purposes. In that respective an initial list of researchers and practitioners can be established, for instance when sharing experiences during the engineering of a capability modelling method or when applying it in a real world setting and validating it against a set of requirements. 


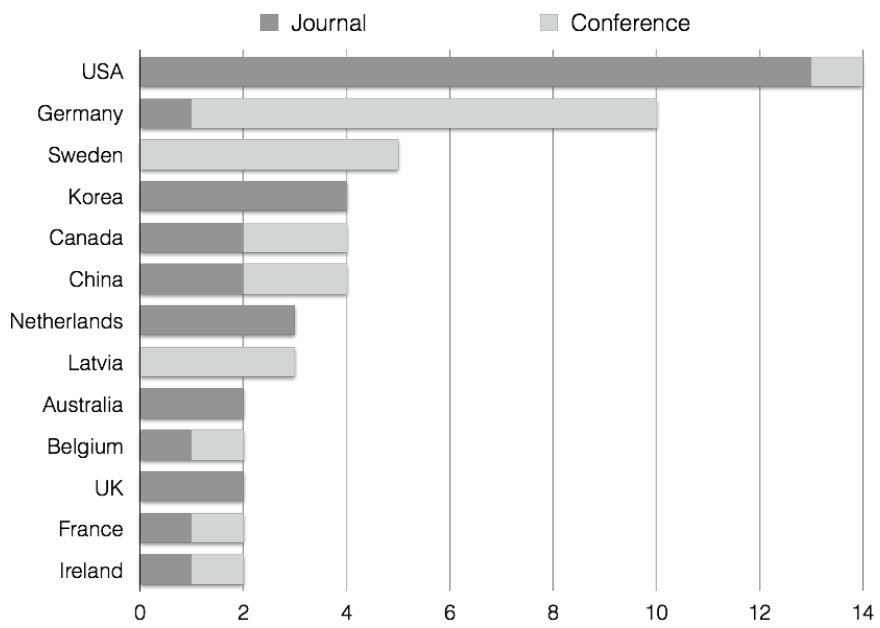

Fig. 5. Articles per countries

\subsection{Methods for Designing and Developing Capabilities}

In line with the method framework presented in section 1 shortly, this section analyses which methods exist to design capabilities and how they are related to the research topics provided in section 4.2.

IS Development. The articles providing methods for capability design based on a novel approach in the capability modelling field, Capability-driven Development (CDD), proposed in [15] are classified here. The CDD approach integrates organisational development with IS development by considering the application context and adjusting the solution in line with the dynamic changes. In this connection [16] presents an approach to design capabilities and establishes first cornerstones of capability development method. [18] addresses the stakeholder concerns to be taken into account when developing capabilities and presents a process for specifying requirements. [19] provides an overview of CDD method components, including context modelling, patterns modelling and enterprise modelling parts. Finally [2] uses the CDD approach on a case study and reports feedbacks for the improvement of CDD methodology.

E-Commerce. The capability design methods for adjustable service provision received attention in the e-commerce field between 2005 and 2009. To exemplify, [20] indicates the need for developing focal capabilities to achieve an e-commerce adoption and presents a process model to orchestrate the organizational resources in line with the changing business delivery context. However no steps, activities and tasks are defined and the approach lacks notation to model the outputs of the phases. [21] suggests strategies for practitioners how to develop organisational capabilities in e-commerce field and provides a process model including the key actions to be carried out.

Business Process Management (BPM). Notably in the last third of the analysed time frame, works in the BPM field relate to the methods in capability design. [22] and 
[23] investigate BPM topic from the Dynamic Capability point of view and present a framework, which supports the design of BPM capabilities. The framework consists of three activities, namely sensing, seizing and transformation, which are further elaborated in sub-capabilities. Last but not least [24] offers a method for IT capability based business process design, which consists of 8 steps. The work describes roles and notations loosely, whereas the important concepts, outputs of the activities are not mentioned at all.

In addition to the above-mentioned topics, [25] proposes a process model for the development of capabilities to meet fast growing business demands. [26] develops a theoretical model for conceptualizing the internationalization strategies of IT vendors, which consists amongst others a capability-building process. Regarding both articles however, the processes cannot be applied solely as a capability design method since the roles, goals, concepts and notation is not defined. Besides, the latter contribution analyses the capabilities of IT service vendors in emerging economies, which remains too specific.

To sum up our findings, the CDD approach provides amongst the investigated publications the most comprehensive methodological support to design enterprisegrade capabilities. This is based on the following reasons. First, the method exploits enterprise models to develop capabilities by explicitly defining the important concepts and notations to represent them. Second, the CDD approach assumes different starting points to develop capabilities, such as business process models, goal models or concept models, which should support different ways of working. Last but not least, the method takes the contextual factors into account, i.e. the realization of enterprise goals can be adapted to changing situations. This is a significant contribution towards the business and IT alignment, since the business-centric concerns can be represented in goal models whereas their actual implementation can be addressed in context models. Apart from the CDD, the analysed articles i) address which factors should be taken into account when designing capabilities, ii) show how they relate to subject under study, iii) provide means for capability evaluation, such as maturity models, iv) focus on capabilities that are decoupled from enterprise goals and v) propose steps, procedures, guidelines to design capabilities, which cannot be developed by analysing the existing enterprise models and stakeholder goals.

\section{Discussion and Conclusions}

This paper contributes to the research field in capability design and development methods by conducting a mapping study as shown in [1] and [6]. In line with the rankings in $[3,4,5]$ a search term was applied to 112 journals and 24 conference proceedings. A number of criteria were defined to include and exclude the articles in the final set. As a result a total of 45 articles were classified into a scheme, i.e. applied research design, used research methods and investigated research topics. To analyse the results and to identify trends we defined three time frames, namely 2000-2004, 2005-2009 and 2010-2014. The trend calculation was done by relating the used terms to the number of published articles in the selected time frame. For instance, the topic business process was investigated in $25 \%$ of the papers that are published between 
2000 and 2004. In doing so, we aimed to hinder the effect of the increase on the number of the articles through the years. Following summarizes the findings of the work.

Research Method \& Design. Empirical research is used extensively in developing and designing capabilities. More than a half of the articles adopting quantitative research conduct surveys and follow a structure consisting of three steps (see section 4.1). Their results can be used when engineering a method for developing and designing capabilities. There seems to be a trend in the capability design field concerning the application of secondary data and case studies as a research method. On the other hand DSR is applied scarcely, which is a certain motivation for further research. In addition to that, if an article combines both qualitative and quantitative research methods, then it more likely adopts a research method pattern, i.e. case studies, interviews and analysis of secondary data are engaged.

Research Topics. The topics related to the enterprise modelling, BPM, Business Models are only analysed in conference proceedings. The articles investigating capabilities are motivated by RBV, however the focus moves towards "changing environment" lately. There might be a correlation between 3 topics, namely capability development, enterprise models and changing environment, which should be falsified or confirmed in the future work.

Activity. Over the years there is a growing interest in developing capabilities. The number of the published articles in this field rose steadily in the conferences. Among the investigated conference proceedings, CAiSE focus most on the design and development of capabilities. The journal articles investigate the frameworks, attributes and the organizational characteristics when designing the capabilities, though the aspects including the methodological support are neglected. Finally, a list of the active countries and research institutes in this field are provided, which might serve practical purposes such as collaboration in the capability development methods area.

Methods. The term "method" is used synonymously with "process, procedure" or "step". Except for the CDD approach we were not able to identify a comprehensive method including stakeholder goals, actors, notations, important concepts and activities to be executed when designing capabilities. Moreover, most of the articles present evidence on how capabilities interact with the subjects under study, such as service quality, customer satisfaction, success factors and knowledge management, but they do not provide further information on how to design such capabilities.

\section{Acknowledgements}

This work has been performed as part of the EU-FP7 funded project no: $611351 \mathrm{CaaS}$ - Capability as a Service in Digital Enterprises.

\section{References}

1. Ulrich W, Rosen M (2011) The Business Capability Map: Building a Foundation for Business/IT Alignment. http://www.cutter.com/content-and-analysis/resourcecenters/enterprise-architecture/sample-our-research/ea110504.html. Accessed February, 2014 
2. Kitchenham, B.: Procedures for Performing Systematic Reviews. Keele University Technical Report TR/SE-0401. July 2004. ISSN:1353-7776. (2004)

3. Schrader,U., Hennig-Thurau, T.: VHB-JOURQUAL2: Method, Results, and Implications of the German Academic Association for Business Research's Journal Ranking. BuR Business Research, Vol. 2, Iss. 2, pp. 180-204 (2009)

4. Peffers, K., Ya, T.: Identifying and Evaluating the Universe of Outlets for Information Systems Research: Ranking the Journals. Journal of Information Technology Theory and Application (JITTA): Vol. 5: Iss. 1, Article 6. (2003)

5. WI-Orientierungslisten. WIRTSCHAFTSINFORMATIK. 50, 155-163 (2008)

6. Webster, J., Watson, R.T.: Analyzing Past to Prepare for Future: Writing a Literature Review. MIS Quart. 26 xiii-xxiii (2002).

7. Wendler, R.: The Maturity of Maturity Model Research: a Systematic Mapping Study. Information and Software Technology, 54(12), 1317-1339. (2012)

8. Hevner, A.R., March, S.T., Park, J., Ram, S.: Design Science in Information Systems Research. MIS Q 28(1): 75-105 (2004)

9. Palvia, P., Leary, D., Mao, E., Midha, V., Pinjani, P., Salam, A.F.: Research Methodologies in MIS: An Update. Communications of the Association for Information Systems: Vol. 14, Article 24. (2004)

10. Myers, M. D.: Qualitative Research in Information Systems. MIS Quarterly (21:2), June 1997,pp. 241-242. Last modified: February 3, 2015 www.qual.auckland.ac.nz (2015)

11. Goldkuhl, G., Lind, M., Seigerroth, U.: Method integration: the need for a learning Perspective. IEE Proceedings, Software (Special issue on Information System Methodologies), Vol. 145, Nr 4. (1998)

12. Alavi, M., Carlson, A.: Review of MIS Research and Disciplinary Development. J. Manage. Inform. Syst. 8, 45-62 (1992)

13. Budgen, D., Turner, M., Brereton, P., Kitchenham, B. Using Mapping Studies in Software Engineering. in: Proceedings of PPIG 2008, pp. 195-204 (2008)

14. Sambamurthy, V., Zmud, R.W.: Research Commentary: The Organizing Logic for an Enterprise's IT Activities in the Digital Era-A Prognosis of Practice and a Call for Research. Information Systems Research 11(2): 105-114. (2000)

15. Stirna, J., Grabis, J., Henkel, M., Zdravkovic, J.: Capability Driven Development - An Approach to Support Evolving Organizations. In: The Practice of Enterprise Modeling, vol 134. Springer Berlin Heidelberg, pp 117-131 (2012)

16. Zdravkovic, J., Stirna, J., Henkel, M., Grabis, J.: Modeling Business Capabilities and Context Dependent Delivery by Cloud Services. In: Advanced Information Systems Engineering, vol 7908. Springer Berlin Heidelberg, pp 369-383 (2013)

17. España, S., González, T., Grabis, J. et al.: Capability-Driven Development of a SOA Platform: A Case Study. In: Advanced Information Systems Engineering Workshops, vol 178. Springer International Publishing, pp 100-11 (2014)

18. Zdravkovic, J., Stirna, J., Kuhr, J., Koç, H.: Requirements Engineering for Capability Driven Development. In: The Practice of Enterprise Modeling, vol 197., pp 193-20 (2014)

19. Sandkuhl, K., Koç, H., Stirna, J.: Context-Aware Business Services: Technological Support for Business and IT-Alignment. In: Business Information Systems Workshops, vol 183. Springer International Publishing, pp 190-20 (2014)

20. Cui, M., Pan, S.: Developing focal capabilities for e-commerce adoption: A resource orchestration perspective. Information \& Management. 52, 200 (2015)

21. Montealegre, R.: A Process Model of Capability Development: Lessons from the Electronic Commerce Strategy at Bolsa de Valores de Guayaquil. Organization Science 13(5): 514-53 (2002)

22. Niehaves, B., Plattfaut, R., Sarker, S.: Understanding Dynamic IS Capabilities for Effective Process Change: A Theoretical Framework and an Empirical Application. ICIS 2011 Proceedings. Paper 11 (2011) 
23. Ortbach, K., Plattfaut, R., Poppelbuss, J., Niehaves, B.: A Dynamic Capability-Based Framework for Business Process Management: Theorizing and Empirical Application. System Science (HICSS), 45th Hawaii International Conference, pp.4287 - 4296, (2012)

24. Adam, S., Ünalan, Ö., Riegel, N., Kerkow, D.: IT Capability-Based Business Process Design through Service-Oriented Requirements Engineering. In: Enterprise, BusinessProcess and Information Systems Modeling, vol 29. Springer, pp 113-125 (2009)

25. Zhou, J., Zuo, M., Li, Q., Xu, W.: Developing An Agile It Capability Accompanying Business's Fast Growing:A Case Study On A Chinese E-Commerce Company. PACIS 2012 Proceedings. Paper 24. (2012)

26. Ning, S.: Internationalization Strategies of IT Vendors from Emerging Economies: The Case of China. ICIS 2008 Proceedings. Paper 96 (2008) 